\title{
Hybridization of Terrestrial Radio and SNSs for Public Engagements is Synergy for Social Capital in Digital Age
}

\author{
Moses Ofome Asak*, Abiodun Salawu \\ Department of Communication, Faculty of Humanities, North West University, Vanderbijlpark, South Africa
}

Email address:

abiodun.salawu@nwu.ac.za (M. O. Asak)

${ }^{*}$ Corresponding author

\section{To cite this article:}

Moses Ofome Asak, Abiodun Salawu. Hybridization of Terrestrial Radio and SNSs for Public Engagements is Synergy for Social Capital in Digital Age. International Journal of Science, Technology and Society. Vol. 7, No. 6, 2019, pp. 93-99. doi: 10.11648/j.ijsts.20190706.13

Received: July 22, 2019; Accepted: August 21, 2019; Published: December 6, 2019

\begin{abstract}
The use of social network sites (SNSs) by people in and outside work settings has become a global phenomenon and this activity is growing at geometric progression. Consequently, the growth of the use of SNSs as a major communication tool now has a relatively greater importance for organizations' continual communication with the public and in building relationships. The use of SNSs today cuts across boundaries and seems to dim the attraction for the use of other forms of digital communication. This is essentially because of its stronger interactive ability to build virtual communities and followers for different organizations and individuals. In this paper, the use of social media, particularly social network sites by traditional radio broadcasting for public engagement is examined to establish its offer of social capital for radio stations, the public and advertisers. The paper draws from McLuhan's Technological Determinism; Katz, Blumler \& Gurevitch Uses and Gratification theories as theoretical foundation in tandem with qualitative analysis of documented relevant literature from which deductions were made. The discourse suggests that radio stations especially in developing countries must step up integrating the use of SNSs for associated socio-economic benefits if the stations are to remain relevant in current digital media landscape.
\end{abstract}

Keywords: Terrestrial Broadcasting, Radio, Social Network Sites, Public Engagement, Social Capital

\section{Introduction}

As at November 2016, the figure of global Internet active users is 3,495,349,351 and still counting [1]. The number of internet users worldwide in 2018, stood at 3.9 billion [2]. This means global Internet active users are now over the 3 billion mark equaling $46 \%$ global population [1,3]. Also, global statistics show that more than half of planet earth now owns a mobile phone, with Internet and social media access exceeding 3.6 billion [4]. Mobile social media use is also on the rise with 2.31 billion social media users, delivering $31 \%$ of global population and with $77 \%$ of all social networking users now accessing via mobile devices $[3,1]$. Indeed, people are increasingly employing mobile devices to engage radio stations on social media platforms.

However, why people use or engage with a radio station's social media platform as a motivational factor in research studies, is also directly related to why radio stations as organizations, use social media for broadcast purposes [5-7]. In this also lies the benefit of social media for organizations and people. We argue in this paper therefore, that radio stations like human entities, have socio-economic needs to satisfy and the gratification of such needs have been expanded with the advent and growth of the use of social media. In this paper we examine relevant literature pertaining to the use of social media by traditional broadcasting for public engagement to establish socio-economic implications for broadcast stations, the public and advertisers. The reviewed literature speaks to a key question: How does the synergy of traditional broadcasting with social media expand socio-economic boundaries for stations, the public and advertisers in a digital world? A theoretical conceptual framework provides a critical map of this field of study to address the concerns about effects of the use of social media on broadcast stations and on society. In this paper, effects are conceptualized as social capital benefits that accrue to broadcast stations and their audiences as well as advertisers. The starting point is some considerations about definitions pertaining to social media because of its relative elasticity as a concept. 
Social media is understood in its simple form in this paper as interactive websites and applications that empower users to engage by creating and sharing content in a social network. However, because of the pervasiveness of social networking sites (SNS), which is a subset of social media, among business organizations and individuals alike, and due to the features of the medium which include low entry cost, convenience and easy usage of the service [8] by broadcast stations and individuals, SNSs is used as a synonym to social media in this paper. Broadcast stations on the other hand, engage in broadcast activities and the audience is what keeps commercial broadcast stations sustainable as a result of advertising revenue which a large station audience attracts. Broadcasting in this paper therefore, refers to the spread or diffusion of programs or content from the mass medium of radio to the public through terrestrial broadcast and on social media platform. Broadcast content extends to social media platforms in order for broadcast stations to enjoy social capital and economic benefits. Bourdieu offered the first contemporary definition of social capital as "the sum of actual or potential resources related to the possession of a durable network of more or less institutionalized relationships of acquaintance and recognition" [9]. This definition suggests that social networks or social relationships are the main component in the definition of social capital. Social capital therefore, equals benefits that can be derived from social relationships. Social relationships are thus, a precondition for social capital [10]. For the purpose of this paper therefore, the focus is on terrestrial radio stations as organizational entities in relationships with their publics on social media in order to gain social capital.

Traditional broadcast stations have attracted much study especially in terms of audience studies over the years just as there is a growing body of knowledge today about the development and use of social media. However, studies about the integration of these two concepts is still relatively scarce particularly with respect to whether audience engagement with broadcast stations actually benefits and make the stations work better. The need for more contribution to the growing body of knowledge in this area becomes very relevant especially against the background of the revenue model of commercial broadcast stations.

\subsection{Significance}

The benefit of social capital in public or audience engagement when SNSs are integrated with traditional radio broadcasting is particularly relevant in sub-Sahara African context where integration of traditional broadcast operations with SNSs is still at developmental stages. Since the concept of social media integration with broadcast stations involves the production and consumption of content by both the sender and receiver, programs can be easily more appealing and interesting with a wider reach. People are provided at all times with issues or programs that concern them as a result of a two-way communication process. This is very important from a development communication perspective because the people become co-producers of messages that affect their lives through discussion of issues presented in radio programs and on social media platform. Such attention and eventual loyalty to traditional radio will further strengthen the sustenance of terrestrial broadcast stations through advertisements for the benefit of the masses that may not be internet savvy. Importantly, the public space of social media expands further the public sphere for Africans to discuss issues particularly when such topical issues are initiated by the broadcast stations that are known to set agenda for the public. Since broadcast time for programs are hardly enough, comments and discussions in a program can easily continue, for example, on social network sites (SNSs) for days, weeks and even months as long as stations continue to actively engage the audience and stimulate the discussions.

To the body of knowledge this paper contributes in the area of social media scholarship and broadcasting as it presents a theoretical framework on how radio stations integrate social media to add value. Such information is also essential for policy development because policymakers, program producers/managers, and implementers are better informed to monitor and evaluate the impact of existing programs and to design new initiatives and innovations for traditional broadcast policies. The implication for practical application provides media practitioners like media managers, producers, media owners and advertisers with a better insight as to how broadcast stations are using social media to engage the public thereby encouraging more use of social media as a result of benefits that accrue in the form of social capital.

\subsection{Theoretical Leanings}

In order to have a better insight into this phenomenon, Technological Determinism and the Uses and Gratification theories were used as a framework in this paper.

Technological Determinism theory posits that human activities in societies are determined by technological factors. The theory postulates that inventions in technology invariably cause cultural change. The electronic media, by extension digital media, have radically altered the way people do things in the midst of a revolution which people are yet to fully come to terms with the studies [11, 12]. McLuhan's theory upholds the maxim that technology determines development and human activities in the society [11]. Griffin explains this further in terms of deterministic theories which maintain that everything in life is connected to a single factor at different points in time [12]. The present era is connected with digital technology.

Marshall Mcluhan propose that the way individuals in a society think, feel and act is fashioned by media technology which also shapes how society at large operates from one era of technology to another [11]. The interpretation of this theory in the context of this paper is important. Users of social media technology tend to behave the way they do now because of the peculiarity of current technology available to them. This is evident in the way most people today can hardly do without cell phones even when they sleep the phones are kept within reach. Also, the technology of radio at 
a time requires people to only listen and develop their sense of hearing. Today the extension of technology in the integration of radio and social media has also extended the senses of man beyond sound to sight because as he listens to radio, he can also read radio digital content and digitally send messages as well. Clearly, this takes away from the old model of traditional radio broadcast.

The relevance of this theory in the light of this paper suggests that the theory has great explanatory power as it explains that with new development in technologies, society and culture also changes in reflecting the senses needed to use the new technology. Akin to this also is the power of parsimony as a simple cause and effect analysis between the introduction of new media technology and the metamorphosis in society's way of thinking, feeling, acting, or behaving. There is also the predictive power of the theory which holds that society will change and adapt to new media technologies. Furthermore, there is an internal consistency in this theory because of the logical flow of proof of evidence over time. In addition, the organizing power of this theory cannot be overruled because in the light of the Internet and social media, we all know that we have developed and have changed in the way we communicate and engage. In a way, this theory provides good reasons why this has happened. However, this theory may be open to falsifiability if nothing happens when a new technology is invented. In the same vein, there is some level of heuristic provocativeness here. Would this theory work in every type of society and culture within and outside USA or will it vary from society to society. And in this digital age, will it vary between the digital divide dichotomies? The seeming inherent limitations in this theory, informs the adoption of a complimentary theory in the Uses and Gratification approach.

\subsection{Uses and Gratification Theory (U\&G)}

Although the Uses and Gratifications theory is generally audience-centered, the argument in this paper is that since radio stations as business enterprises are recognized as legal entities or 'persons' liable to themselves, they also have needs to satisfy just like human beings. In the light of this theory, radio stations seek to satisfy the need for information from and interaction with their audience or public-which ultimately fulfill the need to make profit and sustenance as a business enterprise. Essentially, radio stations over the years have integrated social network sites into their programming in order to expand their audience base. This takes away from Boyd \& Ellison's assertion that we have "a limited understanding of who is and who is not using social media, why and for what purposes" [13]. Also, the fact that commercial radio stations seek to use social media as a tool that eventually contributes to the bottom-line, strengthens what Thrift referred to as 'knowing capitalism' and that 'knowledge which are transmitted through gossip and small talk which often prove surprisingly important are able to be captured and made into opportunities for profit" [14]. De Beer argued that the application of knowledge derived from public engagement with social network sites "inform capitalism by drawing upon forms of knowledge that (may) have largely evaded the business sector" [15]. This buttresses the point that the motivation to use social media by commercial radio stations is ultimately to make profit by attracting listenership and drawing on user-generated content.

The Uses and Gratifications approach which became popular from the works of Katz, Blumler \& Gurevitch, focuses on understanding why and how people use specific media to satisfy specific needs [16]. Katz et.al synthesized that the approach is on "the social and psychological origins of needs, which generate expectations of the mass media or other sources, which lead to differential patterns of media exposure (or engagement in other activities), resulting in need gratifications and other consequences, perhaps mostly unintended ones" [16]. Katz et.al identified elements of the Uses and Gratifications theory which includes the conception of audience as active; the linking of gratification and media choice which lies with the audience member; other sources of satisfaction for the audience competes with the media; in research, data is often supplied by the members of audience for many goals of the use of media to be achieved [16]. Five reasons were advanced by these scholars for why the audience uses media. The reasons include information, education, entertainment, enhancement of social interaction, and escape from stress. The theory is audience-centered and bears directly on the current study as it seek partly to understand why and how the public engage with radio's social media platforms like social network sites.

Importantly, the motivational factor in the Uses and Gratifications theory, complements the weakness in Technological Determinism theory because irrespective of the setting or where social media is used, there will always be reason (s) why people or organizations adopt the use of specific media. The justification of these two theories in this study therefore, lies in the fact that while Technological Determinism provides a foundation and explanations about the exponential embrace and acceptance of the new technology (social media), the Uses and Gratifications theory offers the reasons why people and organizations like radio stations use this new digital technology of social media.

Further explanations and relevance of these theories as propose in Fig. 1 suggest that the digitalization of the media landscape as an antecedent triggered a need as an independent variable in the use of social network sites by traditional radio stations which brings about a dependent variable in public's engagement with radio and makes it possible for radio stations to enjoy (gratification) benefits which may be in form of social capital, also as a dependent variable. Based on the phenomenon discussed in the light of the two theories therefore, a conceptual framework as depicted in the Figure 1 is suggested. 


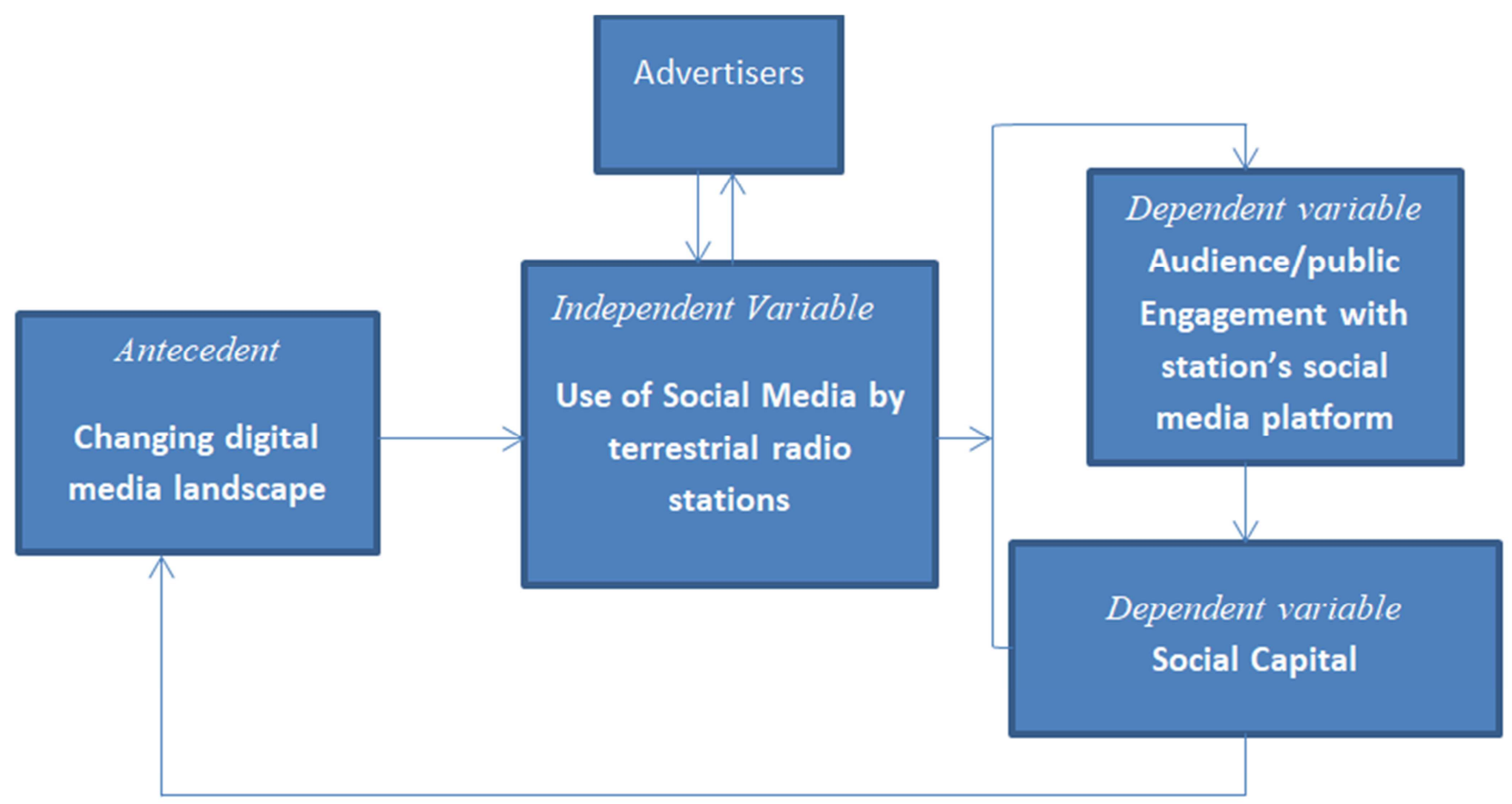

Source: Self-generated by the authors

Figure 1. A conceptual framework of traditional commercial radio stations use of social media for public engagement.

Commercial broadcast stations are increasingly using social network sites. Scholars have also emphasized the importance of social media as a major research area for those interested in online technology and social impacts [17-21]. However, researchers have only recently begun to explore the influence of the use of social media in achieving organizational goals particularly in radio broadcasting [22].

\subsection{Literature}

The review of literature indicates that scholars focus more on broadcast journalists' use of social network sites as against a holistic perspective in this paper, which looks at traditional radio station as a system with journalists as components of the system. Also there is a dearth of literature on relationship between traditional broadcast stations, public engagement and benefits that accrue to stations as a result of social media use. This poses a major threat for the sustainability of traditional radio broadcast stations in subSaharan African developing countries unless the stations in these countries begin to understand benefits in the integration and use of social network sites with traditional forms of broadcasting. This implies a need for broadcast stations to meet or fulfill in the face of competition in a digital media space for them to be sustainable and relevant in the current media dispensation.

New media like social media requires active engagements. By actively engaging with audience during and beyond the broadcast time of any radio program the stations can benefit from social capital that eventually impact positively on the revenue model of commercial broadcast stations. Although stiff competition in the digital media landscape has caused the use of social media by broadcast stations, one is not sure how active the stations are on these platforms. Studies show that broadcast stations are very active on social media platforms in developed countries. The same cannot be said about developing countries. Indeed, one is not sure if such limited use of social media is not just a bandwagon effect in developing countries. The objective therefore is to show the benefits that can accrue to a broadcast station as a business entity from the synergy of terrestrial radio and social media.

\subsubsection{Terrestrial Radio Broadcasting and Social Media: The Synergy Works}

The social media space is relatively new, pervasive and captivating especially with younger audiences, which are more or less elusive to acquire by broadcasters without substantial innovation. Content is king and it has to be part of audience social experience. This can be achieved only if content is relevant, appealing, interesting and on the right platform for audience consumption. Traditional broadcasting has found its inadequacy in old platforms in the face of new media. Thus, narrowing collaborations between social media and traditional broadcasting is manifestation of synergies.

Traditional broadcasting, that is radio and television, has come a long way and the age-long rivalry between the two is brought to an end in the advent of a common ally in social media, specifically social network sites. Broadcasting especially for traditional commercial stations is big business. And sustainability of the business depends not only on good and appealing content but also on delivery of content to broadcast audience/viewers. Beyond that, it requires the building and maintenance of relationships with the audience by broadcast stations. The relatively low cost, high speed and 
ubiquity inherent in the new media created social affordances in content production, delivery and accrual of social capital and economic benefits [23]. The new media landscape provides an environment of computer-mediated communication that supports constant social connectivity of personal ties and larger groups and communities of interest 24. Traditional broadcasting can thrive better with social media because social media on the platform of the Internet facilitate the building of relationships by broadcast stations with their audience thereby contributing to social capital. Social network sites like Facebook, and Twitter affords the increase of connection with close relatives (strong ties) and associates (weak ties) but also creates new ties and activates latent ties thereby affording both bonding and bridging of social capital [25-29].

\subsubsection{The Synergy and Social Capital Outcome}

Social capital according to Bourdieu \& Wacquant refers to "the sum of the resources, actual or virtual, that accrues to an individual or a group by virtue of possessing a durable network of more or less institutionalized relationships of mutual acquaintance and recognition" [28]. Connecting with people on social media platform implies that the integration or synergy of traditional broadcasting is positively related to social capital since research generally supports the positive association between social capital and the Internet on which platform social media thrives [29]. Drawing from the works of scholars this positive association is arranged at three levels [30]. These levels include the Internet as a complement of social capital; the Internet as positively related to social capital; and the Internet as a tool that creates and maintains social capital. The conclusion is that Internet helps to build social capital at different levels by supporting social connectedness; promoting 'networked individualism'; allowing people to put their networks to work when they need help thereby accessing and mobilizing their social capital and because Internet users generally have larger social networks, they potentially tend to have more ties to draw resources from Boase et al. [31].

\subsubsection{The Synergy and Economic Benefits}

The world of broadcasting is gradually integrating itself into the world of social media. There are several ways broadcast stations are doing this ranging from live chat shows where audience members can connect with stations from across the country and beyond [32]. This has expanded the frontiers of the joy of watching or listening to a broadcast program beyond the confines of a room with a group of friends. There are also Forums on station's websites designed for audiences to share their thoughts and provide feedback. Facebook and twitter are currently the most used social media platforms with traditional broadcasting [33].

Broadcasting just like many other businesses must understand how social media can help them promote their services to existing and potential audiences. It is not enough to just join the bandwagon and use social media if the business does not understand how it can add value [34]. Presently, the top social media sites businesses are using are
Twitter, Facebook, YouTube and LinkedIn and there are a variety of economic advantages that accrues from the use of social media despite the debate on whether it actually increase the bottom lines of businesses [35]. First, because the use of social media is easily affordable, integrating it with broadcasting is cost effective. Yet, this affordance attracts an economic benefit of a large audience never before imagined with traditional broadcasting acting alone. Such large audience, if well managed, can translate or convert to a large market to attract advertisers to place their products both onair and on a station's website page. Such media sites can give business owners access to a large market that may patronize them and also give further visibility to the broadcast station brand by allowing the audience to "follow" or "like" the station brand [35]. Furthermore, the question of traditional stations interacting with their audience to build relationships on social media platforms can eventually translate to brand loyalty for the station. In business loyalty in most cases, translate to patronage. This implies that any information shared by stations on their platform on-air or on their website will be accepted because of a strong relationship with the broadcast station. Such relationship is good to attract advertisers who are the mainstay of commercial broadcast stations. This can easily make for brand awareness of not only advertisers products but that of the station's activities as well.

As station's activities occupy top of mind awareness in the audience, so also the stations are better positioned to gain marketplace insights or valuable customer insights. With such knowledge, content can be tailored to specific audience and advertising targeted at right audiences. This ultimately translates to better audience satisfaction and a likelihood of better attention and conversion in the audience to patronize the stations which in turn will attract advertisers' needs for product placement. And the circle revolves again all as a result of a rich audience experience.

\section{Methods}

The method adopted in this paper is in line with qualitative research tradition that is already established in existing theory and research practices. For the purpose of this paper, a desk research of existing literature following systematic guidelines for secondary data collection was used in tandem with a qualitative thematic content analysis. The analysis and deductions from analyzed data were made relative to the phenomenon under study.

The qualitative content analysis was used to examine blog content that relates to radio's use of social media platforms in the digital age. The criteria for selecting the blogs includes: 1. a blog that has in its title concepts related to keywords or the hybridization of radio and social media which constitutes the thrust of this paper. 2. a blog posted not earlier or later than the year 2018. The year 2018 was chosen because it is the most recent and complete year for analysis. A metasearch engine tool was employed to collect the data from social media sites. The meta-crawler search engine tool was 
used to get a list of the blogs and their content. Content analysis of the data reveals three recurrent themes of: 1 . benefits that accrue to radio stations' use of social media; 2 . how radio stations are using social media; 3. predictions of radio use of social media.

\section{Result}

The findings reveal that first, $54 \%$ of the blogs refer to the benefits that radio stations are getting by integrating traditional or terrestrial radio broadcasting with social media platforms like Facebook, Twitter, Instagram, Snapchat etc. Seven per cent of this group of blogs also admit that although the benefits are not tangible and easily calculated or analyzed, they are nevertheless present and constitute more of a social capital that help to increase the bottom-line and offer goodwill for commercial radio stations and public service broadcasting respectively.

Secondly, $33 \%$ of the blogs relate to how radio stations are using social media platforms to leverage other media in this competitive digital media age. This finding show that many radio stations especially in developed countries have integrated with social media as part of their terrestrial radio broadcast policy.

Lastly, $11 \%$ of the blogs foretells the future of hybridization of radio with social media. Part of this group predicts that social media will become a major platform and extension of advertising revenue for radio that is if all radio stations do not eventually end up as internet only radio stations.

\section{Discussion}

The relevant theories of Technological Determinism [11] and the Uses and Gratification theory [16] on which this article builds suggest that the digitalization of the media landscape as an antecedent triggered a need in the use of social network sites by broadcast media, an independent variable, as exemplified in the proposed conceptual framework in Figure 1. The need for the use of social media by broadcast stations is premised on a dire need for an extended audience reach through social media and to disseminate content to a more targeted audience which is also brought about by social media. This brings about a further dependent variable in public's engagement with radio on social media platforms. It makes it possible for radio stations to enjoy (gratification) what is in the form of social capital, also a dependent variable. It is not surprising therefore that the findings in this study suggest that social media is a major utility for radio stations because of the benefits that accrues from its use. This agrees with the findings of other scholars [5-7] on why broadcast stations that understand the necessity to integrate social media are using it to enhance productivity as a result of social capital derived therefrom. Instructively, the social media platforms are fast becoming a platform for advertising radio clients.

Conversely, the pervasive use of social media by broadcast stations is not in consonance with Boyd \& Ellison's assertion that: "we have a limited understanding of who is and who is not using social media, why and for what purposes" [13]. This is not entirely correct because as this paper shows businesses like commercial broadcast stations are using social media and for specific reasons too. One of such reasons is to meet and engage with old and new audiences on digital platforms by expanding their reach through social media platforms. But again, this is not entirely true about developing countries where the use of social media by broadcast stations is more of a bandwagon effect and there is no clear cut measurement of the benefits.

\section{Conclusion}

In conclusion, connecting with people on social media platform implies that the integration or synergy of traditional terrestrial radio broadcasting is positively related to social capital and economic benefits both for the stations and the audience because as Neves' findings show, research generally supports the positive association between social capital and the Internet on which platform social media thrives [29].

\section{Recommendations}

Based on the findings presented in this paper, it is recommended that radio broadcast stations especially in developing countries, should continue to consolidate on the integration of social media with terrestrial forms of broadcasting. Such consolidation should be purpose-driven and not just an exercise embarked upon because everybody is doing social media but more importantly, because social media benefits radio.

The benefits can be further harnessed if radio stations' personnel begin to acquire expert knowledge in the measurement of social capital that accrues from the use of social media by radio stations in more concrete terms as it affects stations' bottom-line. To this end also, the employment of social media managers is paramount because they are vast in the application and knowledge of Application Processing Interfaces (API's) and social media analytics.

\section{References}

[1] Berners-Lee, T. (2016). Internet Live Stats. Retrieved from http://www.internetlivestats.com/internet-users/

[2] Statista (2019). Number of internet users worldwide 2005$2018 . \quad$ Retrieved from https://www.statista.com/statistics/273018/number-ofinternet-users-worldwide

[3] Kemp, S. (2016, January 27). Digital in 2016. [Blog post]. Retrieved from http://wearesocial.com/uk/specialreports/digital-in-2016

[4] Kemp, S. (2014, August 8). Global social media users pass 2 billion. [Blog post]. Retrieved from http://bit.ly/2j65tYb 
[5] Brandtzæg, P. (2012). Social Networking Sites: Their Users and Social Implications-A Longitudinal Study. Journal of Computer-Mediated Communication, 17: 467-488.

[6] González, S. M, Carril, M, Pablo, C, de Sotomayor, Dans, I. (2017). Factors which motivate the use of social networks by students. Psicothema, 29 (2) 204-210.

[7] Matikainen, J. (2015). Motivations for content generation in social media. Participations, 12 (1). Retrieved from https: www.participations.org.

[8] Donath, J. (2007). Signals in social supernets. Journal of Computer-Mediated Communication, 13, 231-251.

[9] Bourdieu, P. (1986). 'The Forms of Capital'. Pp. 46-58 in Handbook of Theory and Research for etc., edited by John E. Richardson. Grennword Press: New York.

[10] Lin, N. (2001). Social capital: A theory of social structure and action. London: Cambridge University Press.

[11] Mcluhan, M. (1962). The Gutenberg galaxy: The making of typographic man. Toronto: University of Toronto Press.

[12] Griffin, E. (2004) A first look at communication theory. New York, NY: McGraw-Hill Company.

[13] Boyd, D. and Ellison, N. B. (2007). "Social Network Sites: Definitions, history and scholarship," Journal of Computer Mediated Communication, 13 (1); 210-30.

[14] Thrift, N. (2005). Knowing capitalism. London: Sage.

[15] Beer, D. (2008). Social network (ing) sites. revisiting the story so far: A response to danah boyd \& Nicole Ellison. Journal of Computer-Mediated Communication. 13, 516-529

[16] Katz, E, Blumler, J. G. and Gurevitch, M. (1973). Uses and Gratifications Research. The Public Opinion Quarterly, 4 (38), 509-23. Retrieved from http://bit.ly/2iANm9E

[17] Boyd, D. and Ellison, N. B. (2007). "Social Network Sites: Definitions, history and scholarship," Journal of Computer Mediated Communication, 13 (1);210-30.

[18] Ellison, N. B, Steinfield, C, Lampe, C (2007). The Benefits of Facebook "Friends:" Social Capital and College Students' Use of Online Social Network Sites. Journal of Computer Mediated Communication. 12 (4), 1143-1168.

[19] Ellison, N. B, Vitak, J, Gray, R, Lampe, C (2014). Cultivating Social Resources on Social Network Sites: Facebook Relationship Maintenance Behaviors and Their Role in Social Capital Processes. Journal of computer mediated communication, 19 (4), 855-870.

[20] Donath, J. (2007). Signals in social supernets. Journal of Computer-Mediated Communication, 13, 231-251.

[21] Steinfield, C, Ellison, N. B, \& Lampe, C. (2008) Social capital, self-esteem, and use of online social network sites: A longitudinal analysis. Journal of Applied Developmental Psychology 29, 434-445.

[22] Paek, H. J., Hove, T., Jung, Y., \& Cole, R. T. (2013). Engagement across three social media platforms: An exploratory study of a cause-related PR campaign. Public Relations Review, 39 (5), 526-533.

[23] Wellman, B, Quan-Haase, A, Boase, J, Chen, W, Hampton, K, Isla de Diaz. I, \& Miyata, K. (2003). 'The Social Affordances of the Internet for Networked Individualism.' Journal of Computer-Mediated Communication 8.

[24] Wellman, B. (2001). 'Physical Place and Cyberspace: The Rise of Personalized Networks.' International Urban and Regional Research 25: 227-252.

[25] Rainie, L, \& Barry Wellman (2012). Networked. Cambridge: MIT Press.

[26] Haythornthwaite, Caroline (2002). 'Strong, Weak, and Latent Ties and the Impact of New Media.' The Information Society 18: 1-17.

[27] Brandtzæg, P.. (2012). 'Social Networking Sites: Their Users and Social Implications-A Longitudinal Study.' Journal of Computer-Mediated Communication 17: 467-488.

[28] Bourdieu, P., \& Wacquant, L. (1992). An Invitation to Reflexive Sociology. Chicago: University of Chicago Press.

[29] Neves, B. B. (2012). 'Social Capital and Internet Usage: A Study in Lisbon.' Doctoral dissertation. Technical University of Lisbon, Portugal.

[30] Bauernschuster, S, Falck, O, \& Woessmann, L. (2011). 'Surfing Alone? The Internet and Social Capital: Evidence from an Unforeseeable Technological Mistake.' IZA Discussion Paper, 5747.

[31] Boase, J, John Horrigan, J, Wellman, B, \& Rainie, L. (2006). The Strength of Internet Ties. Washington, DC: Pew Internet and American Life Project.

[32] Miller, D. (2016). Social media in an English village, 220. UCL Press.

[33] Kietzmann, J. H., Hermkens, K., McCarthy, I. P., \& Silvestre, B. S. (2011). Social media? Get serious! Understanding the functional building blocks of social media. Business horizons, 54 (3), 241-251.

[34] Andzulis, J. M., Panagopoulos, N. G., \& Rapp, A. (2012). A review of social media and implications for the sales process. Journal of Personal Selling \& Sales Management, 32 (3), 305316.

[35] Falls, J., \& Deckers, E. (2011). No bullshit social media: the all-business, no-hype guide to social media marketing. Que Publishing. 